\title{
Article \\ How to Prevent SARS-CoV-2 Transmission in the Agri-Food Industry during the First Pandemic Wave: Effects on Seroprevalence
}

\author{
Ermanno Vitale ${ }^{1, *}$ ], Francesca Vella ${ }^{1}$, Veronica Filetti ${ }^{1}\left(\mathbb{D}\right.$, Luigi Cirrincione $^{2}$, Giuliano Indelicato ${ }^{1}$, \\ Emanuele Cannizzaro ${ }^{2,+}+\left(\right.$ and Venerando Rapisarda ${ }^{1,+}+\mathbb{C}$ \\ 1 Occupational Medicine, Department of Clinical and Experimental Medicine, University of Catania, \\ 95124 Catania, Italy; francescav.89@libero.it (F.V.); verofiletti@gmail.com (V.F.); \\ giulianoindelicato90@gmail.com (G.I.); vrapisarda@unict.it (V.R.) \\ 2 Department of Sciences for Health Promotion and Mother and Child Care "Giuseppe D'Alessandro", \\ University of Palermo, 90127 Palermo, Italy; luigicirrincione@gmail.com (L.C.); \\ emanuele.cannizzaro@unipa.it (E.C.) \\ * Correspondence: ermannovitale@gmail.com \\ + Co-senior authors in alphabetic order.
}

check for updates

Citation: Vitale, E.; Vella, F.; Filetti, V.; Cirrincione, L.; Indelicato, G.; Cannizzaro, E.; Rapisarda, V. How to Prevent SARS-CoV-2 Transmission in the Agri-Food Industry during the First Pandemic Wave: Effects on Seroprevalence. Appl. Sci. 2021, 11, 10051. https://doi.org/10.3390/ app112110051

Academic Editor: Rosanna Di Paola

Received: 13 August 2021

Accepted: 20 October 2021

Published: 27 October 202

Publisher's Note: MDPI stays neutral with regard to jurisdictional claims in published maps and institutional affiliations.

Copyright: (c) 2021 by the authors. Licensee MDPI, Basel, Switzerland. This article is an open access article distributed under the terms and conditions of the Creative Commons Attribution (CC BY) license (https:// creativecommons.org/licenses/by/ $4.0 /)$.
Abstract: During the SARS-CoV-2 pandemic, many workplaces were forced to interrupt their activities or alternatively had to prefer a smart way of working, if this was compatible with their activities, to contain the spread of the virus. Some production activities, on the other hand, continued, such as those belonging to the agri-food sector. The aim of the study was to investigate seroprevalence in the workers of an Italian agri-food company following prevention interventions developed in concert with an occupational physician. An observational cohort study was conducted on a population of $328(100 \%)$ workers of a company in the agri-food sector, located in the Sicilian region, which specialized in the production and distribution of citrus fruits. Only one worker was infected with SARS-CoV-2, which later also developed the immune response. No other worker contracted the infection. In conclusion, the measures implemented identified the positive subject for SARS-CoV-2 at an early stage. This made it possible to avoid contagion between the positive subject and the other workers. The occupational physician was also, in this case, essential in decoding and implementing the rules and guidelines useful for the protection of the health and safety of the worker.

Keywords: SARS-CoV-2; seroprevalence; agri-food; agricultural workers; occupational medicine

\section{Introduction}

On 31 December 2019, Chinese health officials reported a cluster of cases of acute respiratory illness in persons associated with the Hunan seafood and animal market in the city of Wuhan, Hubei Province, in central China [1]. On 9 January 2020, China CDC reported a novel coronavirus $(2019-\mathrm{nCoV})$ as the causative agent of this outbreak, which is phylogenetically in the SARS-CoV clade [2]. The virus was initially referred to as 2019-nCoV but has since been re-named as SARS-CoV-2 by the WHO on 12 February 2020 [3]. Actually, on 21 December 2020, there were 75,479,471 confirmed cases of COVID-19, including 1,686,267 deaths, reported to World Health Organization (WHO) [4]. After the declaration of pandemic status by the WHO on 11 March 2020 all countries have adopted different measures worldwide in order to reduce the spread of the virus $[4,5]$.

Initially unknown, main symptoms were: fever, muscle or joint pain, dry cough, nausea or vomit, loss of taste and smell, oxygen saturation $<95 \%[4,5]$. Some states such as China and Italy closed schools during the first week of the pandemic, with universities, public offices, favoring smart working. Subsequently, there was a lockdown of all work activities, only essential services were guaranteed (hospitals, pharmacies, supermarkets, food supply chain, gas stations and the oil industry, etc.) [6,7]. In the second phase of the 
pandemic, there was a gradual reopening of the previously closed production activities [7]. In particular in Italy, during the first pandemic wave from 1 April 2020 to 30 June 2020 the total number of cases of subjects who had contracted SARS-CoV-2 was 240,578 and in Sicily it was 3081 . However, in the workplace, the number of injuries in this period was 49,986 in Italy and 575 in Sicily. The most affected sector was the health care sector at around $90 \%$. In the sector of production and distribution of basic necessities, the prevalence was around $5 \%[8]$.

To reduce the influence of COVID-19 on workers in any workplace, some control measures were adopted, based on the risk level. In particular, employers have reduced the risk of workers' exposure to SARS-CoV-2 with specific measures based on risk levels in the workplace [9]. Many companies, therefore, had to comply with the guidelines of the Ministries and scientific societies, creating new health protocols in order to reduce the transmission of the virus in the workplace $[9,10]$.

The aim of this study was to improve a security protocol useful for containing the spread of the SARS-CoV-2 virus in a large-scale retail trade company.

\section{Materials and Methods}

\subsection{Study Population}

From 1 April 2020 to 30 June 2020, a prospective cohort study was conducted on a population of workers of a company in the agri-food sector, located in Sicily (Italy), specialized in the production and distribution of citrus fruits.

The company consisted of $350(100 \%)$ workers, $22(6 \%)$ were administrative employees and $328(94 \%)$ were harvesting and processing workers. All administrative workers continued to work remotely in home-working.

Given the purpose of the study, only one inclusion criterion was used: performing work in the business, during the study period; conversely, workers who performed work remotely, even partially, were excluded from the study.

The study was performed in accordance with the guidelines of the Declaration of Helsinki and the procedures were approved by the ethical board of the University Hospital of Catania (Italy) (54/2020/PO).

All workers joined the study and informed consent was obtained from all participants.

Employees were interviewed by a trained occupational physician. Medical records, socio-demographic data, information about smoking habits, alcohol consumption, place of residence and occupational history were collected.

Long-time smokers reported their intensity of smoking (cigarettes/day) and the number of years they had smoked habitually. Pack-years exposure was calculated by multiplying the number of packs of cigarettes smoked per day by the number of years the person has smoked.

\subsection{COVID-19 Risk and Prevention Measures}

All exposed workers were provided with safety shoes, a filter mask for personal respiratory protection (fine particle mask FFP2 in accordance with EU norm EN 95), protective clothing, and gloves.

One hundred and eighty (55\%) were agricultural workers, always operated outside, with ample distance between each other. Moreover, they drove to work each by their own car. Thus, at the workplace, opportunities for interhuman contact were very limited.

Conversely, 148 (45\%) workers who operated at the processing plant operated along the sorting line and in the surrounding areas, which resulted in the impossibility to maintain a wide spacing of more than one meter among workers. Additionally, in this case, the workers reached the workplace each with their own cars.

Therefore, analyzing the working methods and assessing the risks [11]: the 180 agricultural workers had reduced interhuman contacts and therefore a low risk of becoming infected with SARS-CoV-2 in the working environment; while the 148 (45\%) supply chain 
workers, unable to maintain the interhuman distance, although wearing a mask, presented a medium or high risk of exposure to SARS-CoV-2 in the working environment [9-11].

In order to safeguard the health and safety of workers, according to the guidelines of the Italian Ministry of Health as well as to those of the latest scientific literature and major international agencies such as ECDC, OSHA, INAIL, ISS, etc... a safety operating protocol was established to go to the workplace.

In order to implement all the measures to go to the workplace safely, it was necessary to inform each worker. The information was accepted by signature from each worker.

The main information reported was: (a) stay at home in the presence of fever (over $37.5^{\circ} \mathrm{C}$ ) or other flu-like symptoms and to call one's family doctor; (b) do not go and/or stay in the workplace after entry and declare it promptly if dangerous conditions as flu-like symptoms occur, close contact to a patient with confirmed COVID-19 in the previous 14 days, and contact the family doctor; (c) respect all the provisions of the Authorities and the employer in accessing a workplace. In particular, keep a safe distance, observe the rules of hand hygiene and behave correctly in terms of hygiene; (d) inform the employer of the presence of any flu symptoms during work activities, be careful to stay at an adequate distance from the people present.

The entrance to the workplace always took place with a mask correctly worn and it was forbidden to enter if not wearing a mask.

At the workplace entrance, a worker designated by the employer, with a privacy guarantee, took the body temperature by means of a special contact-less thermometer, pointing it directly on the forehead of the worker. In case of detection of a temperature lower than $37.5^{\circ} \mathrm{C}$, the worker continued the screening autonomously, through self-detection of oxygen saturation, using a special pulse oximeter, after washing hands and disinfecting with cotton and alcohol (or an alcohol-based disinfectant) the index finger and then applying the instrument; a symptom informative sheet was visibly placed at the entrance (see Table 1).

Table 1. Checklist to screen workers before entering the workplace.

\begin{tabular}{|c|c|}
\hline $\begin{array}{l}\text { If Your Values Are in This Column } \\
\text { YOU CAN ENTER }\end{array}$ & $\begin{array}{l}\text { If Your Values Are in This Column } \\
\text { YOU CANNOT ENTER }\end{array}$ \\
\hline Body Temperature $\leq 37.5^{\circ} \mathrm{C}$ & Body Temperature $>37.5^{\circ} \mathrm{C}$ \\
\hline Oxygen saturation $>95$ & Oxygen saturation $\leq 95$ \\
\hline You are not having difficulty in breathing & You are having difficulty in breathing \\
\hline You do not have a cough & You have a cough (excluding allergy) \\
\hline You do not have a fever & You have a fever \\
\hline You did not have a fever yesterday & You had a fever yesterday \\
\hline You do not have diarrhea & You have diarrhea \\
\hline You do not feel nauseous & You feel nauseous \\
\hline You do not have vomiting & You have vomiting \\
\hline You have no alterations in the perception of smells & $\begin{array}{l}\text { You have alterations in the perception of } \\
\text { smells }\end{array}$ \\
\hline You do not have altered taste perception & You have altered taste perception \\
\hline You have not widespread muscle pain & You have widespread muscle pain \\
\hline You do not have tearing and redness of the eyes & $\begin{array}{l}\text { You have tearing/redness of the eyes } \\
\text { (excluding allergy) }\end{array}$ \\
\hline You have no nasal congestion and/or runny nose & $\begin{array}{l}\text { You have nasal congestion and/or runny } \\
\text { nose (excluding allergy) }\end{array}$ \\
\hline
\end{tabular}

In the event of self-reported oxygen saturation below $95 \%$ and/or positive symptoms, the worker informed the supervisor to activate the video-consultation procedure with the 
occupational physician and then left the dedicated room for temporary isolation while waiting to be contacted by the occupational physician. Following the video consultation, on the basis of what was found, the doctor decided if the worker could return to the job or if he had to go to his home and contact the doctor by telephone with the possibility of activating the prevention department of the local health authority. In Figure 1 we reported the procedure to go to the workplace.

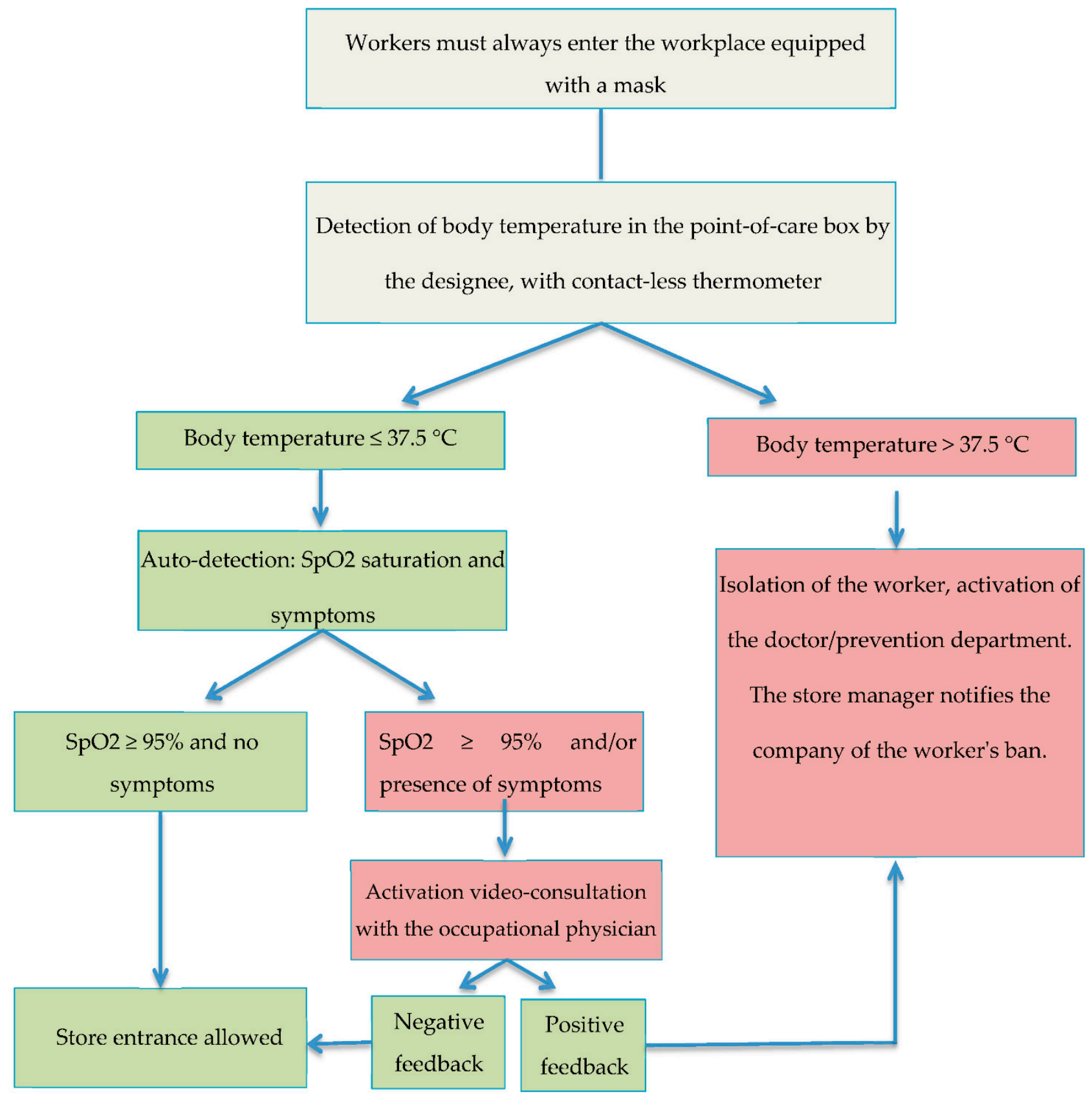

Figure 1. Flow chart with anti-COVID-19 procedures to be followed when entering the company.

\subsection{Health Parameters Measured}

The $328(100 \%)$ participants underwent serologic screening to assess COVID-19. Specifically, the prevalence of SARS-CoV-2 antibody was assessed by qualitative analysis using the COVID-19 IgG/IgM Rapid Test Cassette. This is a rapid chromatographic immunoassay for the qualitative detection of IgG and IgM antibodies against SARS-CoV-2 in human blood (Lumiratek, SD BIOSENSOR, South Korea) $[12,13]$. 
Each worker was tested 3 times during the period examined. The tests were performed at the point-of-care by occupational physicians; antibodies were tested in whole blood Specifically, the test was performed immediately after sample collection: two drops of whole blood $(20 \mu \mathrm{L})$ followed by two drops (approximately $100 \mu \mathrm{L}$ ) of sample diluent were added to the test well. The test results were read and recorded by the physicians after $10 \mathrm{~min}$. The test was considered positive when the IgM and/or IgG band was/was positive. When no control line appeared or if there was difficulty in interpreting the results, the test was immediately repeated. The test was performed by a physician, according to the indications of the parent company.

\subsection{Statistical Analysis}

Statistical analysis was performed with the IBM SPSS Statistics 22.0 software. Normality was checked with the Kolmogorov-Smirnov test. The results were reported as the mean and standard deviation or as frequency and percentage. Multivariate logistic regression was used to explore the relations. Participants were classified into two groups according to the type of work carried out during the period examined: agricultural workers and supply chain workers. Student's $t$-test $(t)$ and Chi-square $\left(X^{2}\right)$ were used to compare the means and frequencies, respectively. A $p$-value of less than 0.05 was considered statistically significant.

\section{Results}

The sample was made up of $328(100 \%)$ workers; of these, $55 \%(n=180)$ were men $45 \%(n=148)$ were women, mean age $43.2 \pm 6.8$, seniority was $17.5 \pm 4.7$. A total of $66 \%$ $(\mathrm{n}=180)$ were smokers. Of these, $62 \%(\mathrm{n}=134)$ had a pack/years value $<20$. A total of $61 \%$ $(n=147)$ drank at least one glass of alcoholic beverage per day (see Table 2).

Table 2. Main sample characteristics.

\begin{tabular}{|c|c|c|c|c|}
\hline \multicolumn{2}{|c|}{ Sample Characteristics } & $\begin{array}{c}\text { Agricultural } \\
\text { Workers } 180 \\
(\mathbf{1 0 0 \% )}\end{array}$ & $\begin{array}{c}\text { Workers in the } \\
\text { Supply Chain } 148 \\
(100 \%)\end{array}$ & $p$-Value \\
\hline \multicolumn{2}{|l|}{ Male } & $177(98 \%)$ & $91(61 \%)$ & $<0.05$ \\
\hline \multicolumn{2}{|l|}{ Age (years) } & $43.6 \pm 7.2$ & $42.2 \pm 5.6$ & n.s. \\
\hline \multicolumn{2}{|c|}{ Years of employment } & $19.5 \pm 5.4$ & $18.5 \pm 4.1$ & n.s. \\
\hline \multicolumn{2}{|l|}{ Smokers } & $145(80 \%)$ & $111(75 \%)$ & n.s. \\
\hline Pack/years & $\begin{array}{l}<20 \\
>20\end{array}$ & $\begin{array}{l}103(71 \%) \\
42(29 \%)\end{array}$ & $\begin{array}{l}84(76 \%) \\
27(24 \%)\end{array}$ & $\begin{array}{l}\text { n.s. } \\
\text { n.s. }\end{array}$ \\
\hline \multicolumn{2}{|l|}{ Alcohol use } & $180(100 \%)$ & $148(100 \%)$ & n.s. \\
\hline \multicolumn{2}{|c|}{ Physical Risks: MMC, Sb, Pi } & $180(100 \%)$ & $148(100 \%)$ & n.s. \\
\hline \multicolumn{2}{|c|}{ Climate risk and UV rays } & $180(100 \%)$ & $17(11 \%)$ & $<0.05$ \\
\hline \multicolumn{2}{|c|}{ Body vibration risk } & $20(11.1 \%)$ & $17(11 \%)$ & n.s. \\
\hline \multicolumn{2}{|l|}{ Chemical Risk } & $21(11.6 \%)$ & $0(0 \%)$ & $<0.05$ \\
\hline COVID-19 risk & $\begin{array}{l}\text { low } \\
\text { medium/high }\end{array}$ & $\begin{array}{c}180(100 \%) \\
0(0 \%)\end{array}$ & $\begin{array}{c}0(0 \%) \\
148(100 \%)\end{array}$ & $\begin{array}{l}<0.05 \\
<0.05\end{array}$ \\
\hline
\end{tabular}

n.s. not significant. $t$-test and Chi-square were used correspondingly to evaluate the means and frequencies.

Table 2 shows the main characteristics of the sample divided into two categories of workers: agricultural workers and supply chain workers.

Occupational health and safety risks for those who worked only as agricultural workers, 180 (55\%), were: manual handling of loads (MMC), biomechanical overload of the upper limbs (SB), incongruous postures (Pi), ultraviolet rays and dust; of these $21(6 \%)$ were also exposed to chemical risks (pesticides users).

For those who worked in the supply chain, the risks were: MMC, SB, Pi. 
$100 \%$ of the workers operated for $40 \mathrm{~h} /$ week, during the first pandemic phase (see Table 2).

Analysis of the two groups shows statistically significant differences for gender, with a significant prevalence of male workers among agricultural workers; no statistically significant difference was found for smoking habits between the two groups. A statistically significant difference was found in the health and safety risks to which workers were exposed. In particular, agricultural workers were significantly exposed to climatic and UV risk and chemical risk (pesticides).

Finally, the COVID-19 risk was significantly different between the two groups, low in agricultural workers and medium in supply chain workers.

The risk classification was based on the documents "Hazard Recognition" by OSHA, 2020 and on the "Technical document on the possible remodeling of measures for the containment of SARS-CoV-2 infection in the workplace and prevention strategies by INAIL, 2020 " [11,14].

During the 3 months under study, all agricultural workers underwent all required procedures before starting work shifts.

For $49(15 \%)$ workers, after applying the anti-COVID-19 operating protocol, it was necessary to contact the occupational physician. Table 3 details the clinical signs/symptoms of these workers.

Table 3. Main clinic/symptoms signal occurred in 49 workers.

\begin{tabular}{cccc}
\hline $\begin{array}{c}\text { Clinical } \\
\text { Signs/Symptoms }\end{array}$ & $\begin{array}{c}\text { Supply Chain Workers } \\
\mathbf{3 2 ( 1 0 0 \% )}\end{array}$ & $\begin{array}{c}\text { Agricultural Workers } \\
\mathbf{1 7}(\mathbf{1 0 0} \%)\end{array}$ & $p$-Values \\
\hline Fever & $20(61 \%)$ & $10(57 \%)$ & n.s. \\
\hline Muscle or joint pain & $6(19 \%)$ & $4(22 \%)$ & n.s. \\
\hline Dry cough & $5(18 \%)$ & $2(11 \%)$ & n.s. \\
\hline Nausea or vomit & $5(8 \%)$ & $1(4 \%)$ & n.s. \\
Loss of taste and smell & $5(8 \%)$ & $1(4 \%)$ & n.s. \\
\hline Oxygen saturation $<95 \%$ & $1(4 \%)$ & $1(4 \%)$ & n.s. \\
\hline n.s. not significant. & & &
\end{tabular}

Forty-nine (15\%) workers entering the company and underwent to anti-COVID-19 protocol showed signs and/or symptoms worthy of attention. In particular, in cases of fever, the worker was sent home and invited to contact the family doctor. In other cases, video consultation with the occupational physician was activated. No statistically significant differences were found between the two groups.

In $3(6 \%)$ out of 30 workers with fever the family doctor prescribed a molecular swab test that gave a positive result for SARS-CoV-2 in 1 case.

In all other cases of workers with symptoms, the video consultation by occupational physician was activated. The workers then observed a home rest period of $4.5 \pm 2.1$ days.

The subject with COVID-19 was placed in isolation by the Prevention Department of the Local Health Authority. The disease had a pauci-symptomatic course, with mild fever $<37^{\circ}$, asthenia, anosmia, ageusia. After the first 10 days of isolation, a second swab was performed with positive results. At 10 days after the second swab, he underwent 2 molecular swabs, $48 \mathrm{~h}$ apart, which were negative. Therefore, according to Italian regulations, isolation was put to an end.

The COVID-19-positive worker was serologically tested for IgG upon return to work.

No other worker developed the disease or immune response even among those who had come into contact with the worker (see Table 4).

During the study period, out of 328 workers, 18 (5\%) of their own accord did not go to work because they were ill. The illnesses/symptoms reported by these were: $9(50 \%)$ fever, $6(33 \%)$ vomiting and or diarrhea, $3(17 \%)$ dry coughing. The molecular swab was carried out at the request of the family doctor at public health facilities given the difficulty of finding it during the first wave of the pandemic. 
The workers were allowed to return to work after 10 days from the first day of absence and after performing the rapid serological test.

None of the workers tested positive for IgM in the rapid serological test. Table 4 reports the immune status of workers against SARS-CoV-2.

Table 4. Immune status between the two groups of workers toward SARS-CoV-2.

\begin{tabular}{lcccccc}
\hline & IgG - & IgG+ & IgM- & IgM+ & NMS & $p$-Values \\
\hline Agricultural workers & $180(55 \%)$ & 0 & $180(55 \%)$ & 0 & 0 & n.s. \\
\hline Supply chain workers & $147(44 \%)$ & $1(1 \%)$ & $148(45 \%)$ & 0 & $1(1 \%)$ & n.s. \\
\hline n.s. not significant; NMS: Nasopharyngeal Molecular Swab Positive. & & &
\end{tabular}

\section{Discussion}

There are over 1 billion agricultural workers in the world [15]. Italy is first in Europe for the number of people employed in this sector, with 1.125 million workers, followed by Spain and France [16-18].

The agri-food production sector, during the first pandemic phase, was one of the few that remained active. In fact, it even increased production activity [6].

Workers employed in the harvesting activity or in the production chain rapidly found themselves wanting to adopt all the necessary measures to face the COVID-19 emergency [19].

Analysis of the two groups revealed statistically significant differences in the health and safety risks to which workers were exposed.

In particular, agricultural workers were significantly exposed to climatic, UV and chemical hazards, unlike workers in the supply chain. The latter, in fact, as mentioned above, carried out most of the time indoor activities and therefore were not directly exposed to UV rays nor to excessive temperature changes. Moreover, they did not deal with the administration of agro pharmaceuticals, therefore chemical hazards were absent.

Finally, the COVID-19 risk significantly differed between the two groups, low in agricultural workers and medium in supply chain workers. This was also indicated by OSHA, 2020 and INAIL, 2020 because indoor workers, due to their work, could not respect the interpersonal distance sufficient to ensure lower contagion risks.

In our study, workers were subjected to a protocol created by a reworking of national legislation and the most recent guidelines.

The results showed us that an effective filter was created on entry into the company to detect the subjects with symptoms suggestive of COVID-19. In fact, 15\% of workers entered the protocol and among these one was found positive for SARS-CoV-2 following the molecular swab performed by the department of prevention.

The main symptoms found in the two groups were: fever, muscle or joint pain, dry cough, nausea or vomiting, loss of taste and smell and values of oxygen saturation $<95 \%$. Excluding the fever, the other symptoms were very nonspecific. In fact, already in the first studies coming from China, the temperature rise was not always present in positive subjects [20]. The protocol adopted, allowed us to identify at an early stage 49 workers who could have escaped only by measuring the temperature.

The seroprevalence study showed that no worker developed anti-SARS-CoV-2 antibodies other than the worker who contracted the virus. This may be attributable to the fact that the SARS-CoV-2 positive worker was identified at an early stage of symptomatology when he was not yet contagious. In fact, many studies showed that asymptomatic and pauci-symptomatic subjects spread the virus less than the symptomatic subjects [21,22].

The limitations of the protocol are related to the fact that during the first pandemic phase, Sicily experienced a low number of infections compared to other regions of northern Italy.

However, the introduction of a protocol that allowed the company to work safely allowed the identification of the positive case to SARS-CoV-2 at an early stage. 


\section{Outcome Measures on Cost-Utility and Budget Impact}

The cost and budget impact of the intervention were low. In particular, the total cost of the kits and medical performance was around EUR 25,000. Considering the company's 2020 turnover (over EUR 50 million), the impact on the company balance sheet considering the risk/benefit ratio has been deposited towards the implementation of the protocol.

\section{Conclusions}

The model used ensured that workers with symptoms suggestive of COVID-19 could not enter the company. This allowed for early detection of the SARS-CoV-2 positive worker and avoided the potential spread of the virus among workers. Moreover, the seroprevalence data confirm that the first pandemic phase marginally affected Sicily.

The role of the occupational physician in contributing to the management of problems related to COVID-19 seems to be central. Employers have quickly found themselves facing a regulatory vulnerability of huge dimensions. The occupational physician was also, in this case, essential in decoding and implementing rules and guidelines useful for the protection of workers' health and safety $[23,24]$.

Author Contributions: Conceptualization, E.V. and V.R.; methodology, E.V. and V.F.; software, E.V. and V.F.; validation, E.C. and V.R.; formal analysis, V.F.; investigation, E.V., F.V., V.F. and G.I.; data curation, E.V. and E.C.; writing—original draft preparation, E.V., V.R.; writing—review and editing, F.V. and G.I.; visualization, L.C.; supervision, V.R.; project administration, E.C., V.R. and E.V. All authors have read and agreed to the published version of the manuscript.

Funding: This research received no external funding.

Institutional Review Board Statement: The study was conducted according to the guidelines of the Declaration of Helsinki. The study was conducted during the activities of the occupational physician according to the Italian legislative decree 81/08.

Informed Consent Statement: Informed consent was obtained from all subjects during the activities of the occupational physician according to the Italian legislative decree 81/08.

Data Availability Statement: Data available on request due to restrictions e.g., privacy. The data presented in this study are available on request from the corresponding author.

Conflicts of Interest: The authors declare no conflict of interest.

\section{References}

1. Patel, A.; Jernigan, D.B. 2019-nCoV CDC Response Team. Initial Public Health Response and Interim Clinical Guidance for the 2019 Novel Coronavirus Outbreak-United States, December 31, 2019-February 4, 2020. MMWR Morb. Mortal. Wkly. Rep. 2020, 69, 140-146. [CrossRef] [PubMed]

2. European Centre for Disease Prevention and Control (ECDC). Contact Tracing: Public Health Management of Persons, Including Healthcare Workers, Having Had Contact with COVID-19 Cases in the European Union-First Update 31 March 2020. Available online: https: / / www.ecdc.europa.eu/sites/default/files/documents / Public-health-management-persons-contact-novelcoronavirus-cases-2020-03-31.pdf (accessed on 27 October 2020).

3. Koh, D. Occupational risks for COVID-19 infection. Occup. Med. 2020, 70, 3-5. [CrossRef] [PubMed]

4. World Health Assocation (WHO). Director-General's Opening Remarks at the Media Briefing on COVID-19-11 March 2020. 14 February 2020. Available online: https://www.who.int/director-general/speeches/detail/who-director-general-s-openingremarks-at-the-media-briefing-on-covid-19 (accessed on 11 May 2020).

5. Feng, S.; Shen, C.; Xia, N.; Song, W.; Fan, M.; Cowling, B.J. Rational use of face masks in the COVID-19 pandemic. Lancet Respir. Med. 2020, 8, 434-436. [CrossRef]

6. State Council, China Guidelines for the Selection and Use of Different Types of Masks for Preventing New Coronavirus Infection in Different Populations 2020. 5 February 2020. Available online: http://www.gov.cn/xinwen/2020-02/05/content_5474774.htm (accessed on 25 April 2020). (In Chinese)

7. Io Resto a Casa (Stay at Home) Decree Was Approved. Available online: http://www.salute.gov.it/portale/news/p3_2_1_1_1 .jsp?lingua $=$ italiano\&menu=notizie $\& \mathrm{p}=$ dalministero\&id $=4186$ (accessed on 26 April 2020).

8. Italian National Institute for Insurance against Industrial Injuries INAIL 2020. Available online: https://www.inail.it/cs/ internet/comunicazione/news-ed-eventi/news/news-denunce-contagi-covid-30-giugno-2020.html (accessed on 5 July 2020).

9. Belingheri, M.; Paladino, M.E.; Riva, M.A. COVID-19: Health prevention and control in non-healthcare settings. Occup. Med. 2020, 70, 82-83. [CrossRef] [PubMed] 
10. George, R.; George, A. Prevention of COVID-19 in the workplace. S. Afr. Med. J. 2020, 110, 269-270. [CrossRef] [PubMed]

11. Occupational Safety and Health Administration (OSHA). COVID-19: Back to the Workplace. Adapting Workplaces and Protecting Workers. Available online: https://osha.europa.eu/it/publications/covid-19-back-workplace-adapting-workplacesand-protecting-workers/view (accessed on 29 April 2020).

12. Tollånes, M.C.; Bakken Kran, A.M.; Abildsnes, E.; Jenum, P.A.; Breivik, A.C.; Sandberg, S. Evaluation of eleven rapid tests for detection of antibodies against SARS-CoV-2. Clin. Chem. Lab. Med. 2020, 58, 1595-1600. [CrossRef] [PubMed]

13. Hoffman, T.; Nissen, K.; Krambrich, J.; Rönnberg, B.; Akaberi, D.; Esmaeilzadeh, M.; Salaneck, E.; Lindahl, J.; Lundkvist, Å. Evaluation of a COVID-19 IgM and IgG rapid test; an efficient tool for assessment of past exposure to SARS-CoV-2. Infect Ecol. Epidemiol. 2020, 10, 1754538. [CrossRef] [PubMed]

14. Italian National Institute for Insurance against Industrial Injuries (INAIL). Coronavirus, Containment and Prevention in the Workplace. Available online: https://www.inail.it/cs/internet/comunicazione/news-ed-eventi/news/news-coronavirus-fase2-documento-tecnico-lavoro-2020.html (accessed on 28 April 2020).

15. International Labour Organization (ILO). Agriculture; Plantations; Other Rural Sectors. Available online: https://www.ilo.org/ global/industries-and-sectors/agriculture-plantations-other-rural-sectors/lang--en/index.htm (accessed on 6 May 2020).

16. Kaźmierczak-Siedlecka, K.; Vitale, E.; Makarewicz, W. COVID-19-gastrointestinal and gut microbiota-related aspects. Eur. Rev. Med. Pharmacol. Sci. 2020, 24, 10853-10859.

17. Italian National Institut of Statistic (ISTAT). Capitale Umano E Stratificazione Sociale Nell'italia Agricola Secondo il $6^{\circ}$ Censimento Generale Dell'agricoltura. Available online: https: / www.istat.it/it/files / /2013/07/Italia_agricola.pdf (accessed on 19 December 2020).

18. Italian National Institute for Insurance against Industrial Injuries (INAIL). Trend of Injuries at Work and Professional Diseases. Available online: https://www.inail.it/cs/internet/docs/alg-dati-inail-2020-marzo.pdf (accessed on 2 January 2021).

19. Maugeri, A.; Barchitta, M.; Battiato, S.; Agodi, A. Modeling the Novel Coronavirus (SARS-CoV-2) Outbreak in Sicily, Italy. Int. J. Environ. Res. Public Health 2020, 17, 4964. [CrossRef]

20. Chen, N.; Zhou, M.; Dong, X.; Qu, J.; Gong, F.; Han, Y. Epidemiological and clinical characteristics of 99 cases of 2019 novel coronavirus pneumonia in Wuhan, China: A descriptive study. Lancet 2020, 395, 507-513. [CrossRef]

21. Gao, M.; Yang, L.; Chen, X.; Deng, Y.; Yang, S.; Xu, H.; Chen, Z.; Gao, X. A study on infectivity of asymptomatic SARS-CoV-2 carriers. Respir. Med. 2020, 169, 106026. [CrossRef]

22. Nicastri, E.; D’Abramo, A.; Faggioni, G.; De Santis, R.; Mariano, A.; Lepore, L.; Molinari, F.; Petralito, G.; Fillo, S.; Munzi, D.; et al. Coronavirus disease (COVID-19) in a pauci-symptomatic patient: Epidemiological and clinical challenge in settings with limited community transmission. Euro Surveill. 2020, 25, 2000230. [CrossRef] [PubMed]

23. Ramaci, T.; Pellerone, M.; Ledda, C.; Rapisarda, V. Health promotion, psychological distress, and disease prevention in the workplace: A cross-sectional study of Italian adults. Risk Manag. Healthc. Policy 2017, 10, 167-175. [CrossRef] [PubMed]

24. Rapisarda, V.; Ledda, C.; Migliore, M.; Salemi, R.; Musumeci, A.; Bracci, M.; Marconi, A.; Loreto, C.; Libra, M. FBLN-3 as a biomarker of pleural plaques in workers occupationally exposed to carcinogenic fibers: A pilot study. Future Oncol. 2015, 11 (Suppl. 24), 35-37. [CrossRef] 